Herbert Küpper*

\title{
Ungarns neues Strafgesetzbuch
}

\begin{abstract}
Hungary's New Criminal Code

In 2012, Hungary enacted a new Criminal Code. The Fidesz government intended this law to embody their 'new', i. e. stricter criminal policy. The core piece of that policy, a sort of 'three-strikes-and-you-are out' rule, was very soon struck down by the then still independent Constitutional Court. In general, the code has the tendency to impose higher punishments than its precursor, but we can find the opposite tendency as well, in particular in the field of petty crime against material values. Life-long imprisonment may mean now imprisonment until death without release; the European Court of Human Rights, however, mitigated some of the more inhuman traits of that concept. In another point, the code openly contradicts several judgements of the ECtHR: using the red star continues to be a crime in Hungary. In the General Part it is noticeable that the code continues the socialist category of 'dangerous to the society'. In the timeline prior to the attempt of a crime lies the 'preparation' of a crime which is now punishable in quite a few cases. For some crimes, the age of responsibility was lowered from 14 to 12 years. The Special Part is not so very different from other continental criminal codes. It contains a large number of 'modern' crimes such as genetic or medical crimes or violations of international sanctions. These provisions have been an empty shell so far. Also the quite impressive range of corruption crimes has remained inactive because the Procurator General defines his principal task to protect the inner power circle and their oligarchs from indictments of their - more and more overt - corrupt practices. In some cases special provisions support various government policies, e.g. the crimes protecting the border fence on the southern border, the punishment of persons and organisations who help refugees, or, quite recently, the highly conflictual paragraph on media coverage of anti-corona measures which, i. a. due to its vagueness, may be abused in order to silence critical journalism.
\end{abstract}

Keywords: Hungary, Criminal Code, General Part, Special Part, corruption crimes, European Court of Human Rights, Hungarian Constitution of 2011, media crimes

\section{Einleitung}

Am 13. Juli 2012 erging in Ungarn eine Neuregelung des materiellen Strafrechts: Gesetz 2012:C über das Strafgesetzbuch (StGB). ${ }^{1}$ Es trat am 1. Juli 2013 in Kraft. ${ }^{2}$ Die

* Herbert Küpper, Prof. Dr. jur. Dr. h. c., Institut für Ostrecht München.

1 Gesetz 2012:C über das Strafgesetzbuch v. 13.7.2012, Magyar Közlöny (ungar. Gesetzblatt, abgekürzt MK) 2012 Nr. 92 S. 13450.

$2 \S 463 \mathrm{StGB}$. 
Regelungen für den Übergang vom alten zum neuen Recht sowie die Anpassungen anderer Gesetze an den neuen Strafkodex traf ein gesondertes Einführungsgesetz (EG-StGB). ${ }^{3}$ Das StGB ist der Kern eines Gesetzgebungspakets, das auch das Verfahrens- und das Ordnungswidrigkeitenrecht ${ }^{4}$ umfasst.

Das neue StGB steht in einer längeren Tradition der Strafrechtskodifikation, die mit dem Strafgesetzbuch von $1878^{5}$ ihren Anfang nahm. Jener sog. Csemegi-Kodex erregte wegen seiner technisch-legistischen Qualität und dogmatischen Höhe auch im Ausland Aufmerksamkeit und wurde v.a. in Südosteuropa rezipiert. ${ }^{6}$ Nach der kommunistischen Machtübernahme erging ein den ideologischen Vorgaben entsprechender Allgemeiner Teil, ${ }^{7}$ und zahlreiche Sondergesetze höhlten die rechtsstaatliche Substanz sowohl des materiellen Strafrechts als auch des Strafverfahrens aus. 1962 trat ein genuin sozialistischer Kodex in Kraft. ${ }^{8}$ Dieser wiederum wurde durch das StGB von 1978 ersetzt, das in die Reformgesetzgebung seit 1968 eingebettet war und gegenüber der Vorgängerregelung von 1961 höhere rechtsstaatliche und dogmatische Standards verwirklichte. ${ }^{9}$ Die enormen Änderungen, die das Ende des Sozialismus und später die Mitgliedschaft in der $\mathrm{EU}^{10} \mathrm{im}$ Strafrecht notwendig machten, wurden in dem StGB von 1978 durchgeführt. Noch vor der Jahrtausendwende begannen die Vorarbeiten an einer Neukodifizierung, zu deren wissenschaftlicher Begleitung eine eigene Zeitschrift, „Büntetőjogi Kodifikáció“ (2000-2008), gegründet wurde.

Die seit 2010 amtierende Regierung Orbán beschleunigte die Arbeit der Kodifikationskommission. Sie begründete die Neukodifikation einerseits mit der Notwendigkeit einer Bereinigung und Konsolidierung des Rechtsstoffs, was innerhalb des seit seinem Erlass mehr als hundertmal geänderten Gesetzestextes nicht möglich sei. An-

3 Gesetz 2012:CCXXIII über die Übergangsbestimmungen in Verbindung mit dem Inkrafttreten des Gesetzes 2012:C über das Strafgesetzbuch (...) v. 28.12.2012, MK 2012 Nr. 181 S. 37409.

4 Gesetz 2017:XC über das Strafverfahren v. 26.6.2017 (StPO), MK 2017 Nr. 99 S. 9484; Gesetz 2012:II über die Ordnungswidrigkeiten, über das Ordnungswidrigkeitenverfahren und über das Ordnungswidrigkeitenregistersystem (OWiG) v. 6.1.2012, MK 2012 Nr. 2 S. 317.

5 Gesetzesartikel 1878:V das ungarische Strafgesetzbuch über die Straftaten und die Vergehen v. 29.5.1878. $\mathrm{Zu}$ den historischen Kontinuitäten und Brüchen im weiteren Verlauf der Strafrechtsgeschichte $M$. Tóth, Magyarország negyedik Büntető Törvénykönyve, Jogtudományi Közlöny 2014 S. 439-452.

6 Näher zum Csemegi-Kodex und seiner Ausstrahlung ins zeitgenössische Ausland L. Fayer, A magyar büntetöjog kézikönyve, 2 Bde., Budapest 1896/1905; H. Küpper, Einführung in die Rechtsgeschichte Osteuropas, Frankfurt/M. 2005, S. 308-309, 316, 398; G. Máthé, W. Ogris (Hrsg.), Die Entwicklung der österreichisch-ungarischen Strafrechtskodifikationen im XIX.-XX. Jahrhundert, Budapest 1996.

7 Gesetz 1950:II über den allgemeinen Teil des Strafgesetzbuchs v. 18.5.1950. Zu den wichtigsten Änderungen gehörten die Einführung der Sozialgefährlichkeit als eine Voraussetzung der Strafbarkeit, die Reduzierung der Tatarten von drei auf zwei (Vergehen, Verbrechen; die Übertretung entfiel) und die Einführung der Strafart der Besserungsarbeit.

8 Gesetz 1961:V über das Strafgesetzbuch der Volksrepublik Ungarn v. 22.12.1961, MK 1961 Nr. 97 S. 939.

9 Gesetz 1978:IV über das Strafgesetzbuch v. 31.12.1978, MK 1978 Nr. 92 S. 1047.

10 H. Küpper, Die Entwicklung des ungarischen Strafrechts seit dem EU-Beitritt, in: ders. (Hrsg.): Von Kontinuitäten und Brüchen: Ostrecht im Wandel der Zeiten. FS für FriedrichChristian Schroeder, Frankfurt/M. 2011, S. 141-163. 
dererseits sollte das neue StGB auch das Symbol einer deutlich schärferen Kriminalpolitik werden, v.a. gegenüber Rückfalltätern. ${ }^{11}$ Der erste Zweck ist möglicherweise zum Zeitpunkt des Erlasses durch das textlich geglättete neue StGB verwirklicht worden; seit 2012 ist es aber schon so oft wieder geändert worden, dass es fast ebenso sehr zu einem Flickenteppich geworden ist, wie es das alte Gesetz von 1978 war. ${ }^{12}$ Die Umsetzung des zweiten Zwecks lässt sich nur beschränkt nachprüfen; die statistisch nachgewiesenen Änderungen im Bereich der verhängten Strafen, der Gefängnispopulation und der Aufklärungsquote verbleiben im Vergleich vor/nach 2012 im üblichen, auch schon vor 2012 feststellbaren Schwankungsbereich. ${ }^{13}$

\section{I. Überblick}

Das StGB besteht aus drei textlich sauber getrennten Teilen: einem „Allgemeinen Teil“ (§§ 1-141), einem „Besonderen Teil“ (§§ 142-458) und einem „Schlussteil“ (§§ 459-465). ${ }^{14}$ Der Schlussteil enthält Legaldefinitionen, die Wertgrenzen, unterhalb derer eine Straftat nur noch eine Ordnungswidrigkeit ist, Vorschriften zum Inkrafttreten und zum Außerkraftsetzen des alten Rechts sowie eine lange Liste der EU-Akte, die das neue Recht umsetzen oder berücksichtigen will. Eine derartige Rechtsharmonisierungsklausel findet sich am Ende zahlreicher ungarischer Gesetze. §405 nennt u. a. die Richtlinien zum Kindesmissbrauch, zum Menschenhandel und zur Schwarzbeschäftigung, das EU-Drogen- und Umweltstrafrecht, die Korruptionsbekämpfung ${ }^{15}$ sowie zahlreiche weitere EU-Vorschriften mit teils oder ganz strafrechtlichem Inhalt.

11 Diese Gründe nennt die offizielle Regierungsbegründung zur Vorlage des Entwurfs des neuen StGB.

12 Skeptisch gegenüber der „permanenten Gesetzgebung“ Tóth (Fn. 5), S. 451; M. Tóth, A Btk. első négy éve, Magyar Jog 2018 S. 15-22 (15-16).

13 Statistiken bei Tóth (Fn. 12) S. 16-18. Die Rate der Gefängnispopulation ist in Ungarn im Vergleich zu vielen anderen europäischen Staaten hoch und belief sich 2018 auf $173 \mathrm{Ge}-$ fängnisinsassen pro 100.000 Einwohner. Zum Vergleich: Für Deutschland betrug dieser Wert 78, für Österreich 98 und für Rumänien 106. Höhere Raten als Ungarn wiesen z. B. Russland (368) oder Litauen (235) auf (World Prison Brief: https://prisonstudies.org/countr $\mathrm{y} /$ hungary).

$14 \S \S$ ohne Gesetzesbezeichnung sind in der Folge die des StGB.

15 RL 2011/93/EU des Europäischen Parlaments und des Rates vom 13. Dezember 2011 zur Bekämpfung des sexuellen Missbrauchs und der sexuellen Ausbeutung von Kindern sowie der Kinderpornografie sowie zur Ersetzung des Rahmenbeschlusses 2004/68/JI des Rates; RL 2011/36/EU des Europäischen Parlaments und des Rates vom 5. April 2011 zur Verhütung und Bekämpfung des Menschenhandels und zum Schutz seiner Opfer sowie zur Ersetzung des Rahmenbeschlusses 2002/629/JI des Rates; RL 2009/52/EG des Europäischen Parlaments und des Rates vom 18. Juni 2009 über Mindeststandards für Sanktionen und Maßnahmen gegen Arbeitgeber, die Drittstaatsangehörige ohne rechtmäßigen Aufenthalt beschäftigen; Rahmenbeschluss 2004/757/JI des Rates vom 25. Oktober 2004 zur Festlegung von Mindestvorschriften über die Tatbestandsmerkmale strafbarer Handlungen und die Strafen im Bereich des illegalen Drogenhandels; RL 2008/99/EG des Europäischen Parlaments und des Rates vom 19. November 2008 über den strafrechtlichen Schutz der Umwelt; Rahmenbeschluss 2003/568/JI des Rates vom 22. Juli 2003 zur Bekämpfung der Bestechung im privaten Sektor. Hierzu s. I. L. Gál, M. Tóth, Az uniós jog és a magyar jogrendszer 
Der „Allgemeine Teil“ regelt in zwölf Kapiteln sehr unterschiedliche Aspekte des materiellen Strafrechts. Kap. I enthält den Grundsatz des nullum crimen, nulla poena. Kap. II regelt die internationale Zuständigkeit Ungarns und Kap. III die Grundlagen des Tatbegriffs mit Vorschriften zu Vorsatz und Fahrlässigkeit, zu Tatmehrheit und fortlaufend begangenen Taten, zu erfolgsqualifizierten Delikten, zum Versuch, zur Vorbereitung und zu den Täter- und Teilnehmerformen. Es folgen Kapitel über die Strafausschließungsgründe, sonstige Hindernisse der Bestrafung, die Strafen, Maßnahmen, die Strafzumessung, das System der Vorstrafen, Sonderregeln für Minderjährige, die das im Übrigen nicht vorhandene Jugendstrafrecht ersetzen, sowie Besonderheiten für Straftaten von oder gegen Militärangehörige.

Der „Besondere Teil“ listet die Straftatbestände auf. Die einzelnen Kapitel des BT orientieren sich an den Schutzgütern und gruppieren Straftaten gegen dasselbe Schutzgut zueinander. Das erste Kapitel des BT enthält die Straftaten gegen die Menschlichkeit, wozu auch Völkermord und Apartheid zählen. Es folgen Kapitel über Kriegsverbrechen, Straftaten gegen das Leben, die körperliche Unversehrtheit und die Gesundheit, Straftaten gegen die Ordnung medizinischer Eingriffe und Forschungen, gesundheitsgefährdende Straftaten, Straftaten gegen die menschliche Freiheit, Sexualstraftaten, Straftaten gegen die Interessen von Kindern und die Familie, Straftaten gegen die Menschenwürde und die Grundrechte, Verkehrsdelikte, Umwelttaten, Straftaten gegen den Staat, Straftaten gegen qualifizierte Daten und das nationale Datenvermögen, Straftaten gegen die Justiz, Korruptionstaten, Amtsdelikte, Taten gegen Amtspersonen, Straftaten gegen die öffentliche Sicherheit, Verstöße gegen völkerrechtliche Embargos u. ä., Straftaten gegen die öffentliche Ruhe, Taten gegen das öffentliche Vertrauen, worunter Urkundsdelikte, Verfälschungen bestimmter Angaben sowie die verbotene Beeinflussung von Sportergebnissen gefasst werden, Straftaten gegen die öffentliche Verwaltung, Gewaltdelikte gegen das Vermögen, Vermögensdelikte, Taten gegen das geistige Eigentum, Geld- und Markenfälschung, Taten zu Lasten des Staatshaushalts, Geldwäsche, Straftaten gegen die ordentliche Wirtschaftsführung, Taten gegen Verbraucherinteressen und die Lauterkeit des Wettbewerbs, Datenverbrechen, Straftaten gegen die Wehrdienstpflicht, die allerdings erst dann Bedeutung erlangen werden, falls die Wehrpflicht wieder eingeführt werden sollte, ${ }^{16}$ und schließlich die Militärstraftaten.

\section{Verfassungsrechtliche Rahmenbedingungen}

Etwa zeitgleich mit dem StGB wurde auch eine neue Verfassung erlassen: Ungarns Grundgesetz vom 25. April 2011. ${ }^{17}$ Es enthält die üblichen rechtsstaatlichen Einhegungen der staatlichen Strafgewalt und Verfahrensgrundrechte in der Strafrechtspfle-

viszonya - büntető anyagi jogi jogharmonizáció, in P. Tilk (Hrsg.), Az uniós jog és a magyar jogrendszer viszonya, Pécs 2016, S. 463-494. Zu völkerrechtlichen Verträgen, die den Inhalt des StGB beeinflusst haben, s. Á. Kara, Nemzetközi kötelezettségek, ajánlások és az új Btk., Jogtudományi Közlöny 2015 S. 453-464.

16 Die allgemeine Wehrpflicht wurde zum 1.1.2012 abgeschafft; seitdem ist die ungarische Armee eine Berufsarmee.

17 MK 2011 Nr. 43 S. 10656. 
ge: das Verbot von Folter, unmenschlichen und erniedrigenden Strafen (Art. III. Abs. 1 GrundG), die persönliche Freiheit und die rechtsstaatlichen Bindungen staatlicher Freiheitsbeschränkung (Art. IV. GrundG) i. V. m. mit dem Recht auf einen fairen Prozess (Art. XXVIII. Abs. 1, 3, 7 GrundG), die Unschuldsvermutung (Art. XXVIII. Abs. 2 GrundG), das Rückwirkungsverbot im Strafrecht (Art. XXVIII. Abs. 4-5 GrundG), ${ }^{18}$ den Grundsatz ne bis in idem (Art. XXVIII. Abs. 6 GrundG) und das Verbot der Ausweisung und Auslieferung von Ausländern in Staaten, in denen ihren die Todesstrafe, Folter oder unmenschliche Behandlung und Strafe drohen (Art. XIV. Abs. 3 GrundG). Das Recht auf Leben in Art. II. S. 2 GrundG wird als Verbot der Todesstrafe verstanden. ${ }^{19}$ Während der Kodifikation des GrundG forderten extremere Stimmen die Wiedereinführung der Todesstrafe, konnten sich aber nicht durchsetzen. ${ }^{20}$ Die immer wieder einmal versuchte Einführung der Todesstrafe auf direktdemokratischem Wege scheitert an dem Verbot von Referenden über Verfassungsänderungen und über die Pflichten aus völkerrechtlichen Verträgen in Art. 8 Abs. 3 Buchst. a), d) GrundG, denn Ungarn hat sich durch die Zeichnung der EMRK zur Abschaffung der Todesstrafe verpflichtet. Art. IV. Abs. 2 S. 2 GrundG erlaubt eine tatsächlich lebenslang dauernde Freiheitsstrafe nur bei vorsätzlichen Gewalttaten. Damit weitet das GrundG die Anwendbarkeit der tatsächlich lebenslangen Freiheitsstrafe im Vergleich zum vorigen Rechtszustand spürbar aus, steckt aber andererseits auch die Grenzen ihrer einfach-gesetzlichen Androhung ab. ${ }^{21}$ Der Verlust des Wahlrechts als Strafart hat seine verfassungsrechtliche Grundlage in Art. XXIII. Abs. 6 S. 1 GrundG. Aus dem Rechtsstaatsgebot des Art. B) Abs. 2 GrundG wird für Strafvorschriften ein gesteigertes Eindeutigkeitsgebot abgeleitet. ${ }^{22}$ Parlamentsabgeordnete genießen Immunität und Indemnität (Art. 4 Abs. 2 S. 1, Abs. 4 GrundG), und die Person des Staatspräsidenten ist „unverletzlich“ (Art. 12 Abs. 1 GrundG), was ihn eine Art Immunität verleiht, die Art. 13 Abs. 1 GrundG präzisiert, und was dem Staat Schutzpflichten zur Bewahrung des Präsidenten vor Angriffen Dritter auferlegt. ${ }^{23}$

Ungewöhnlich ist das Grundrecht in Art. V. GrundG, sich im Rahmen des Gesetzes gegen rechtswidrige Angriffe gegen seine Person oder sein Eigentum zur Wehr zu setzen; eine Nothilfe zugunsten anderer wird in dieser Norm nicht angesprochen. Weil die ungarische Rechtspraxis und -literatur mit dieser Norm nicht viel anzufangen

18 Die Strafandrohung zum Tatzeitpunkt kann sich aus dem ungarischen Recht, aus dem allgemeinen Völkerrecht oder aus dem Recht eines anderen Staates, das gemäß einem völkerrechtlichen Vertrag oder Unionsrecht anwendbar ist, ergeben.

19 So schon für die alte Verfassung Verfassungsgerichtsentscheidung (VerfGE) 23/1990. (X. 31.) AB v. 31.10.1990; hierzu s. G. Brunner, L. Sólyom, Verfassungsgerichtsbarkeit in Ungarn, Baden-Baden 1995, S. 54, 71-72.

20 Zur Diskussion um die Todesstrafe s. M. Tóth, Einführung in das ungarische Strafrecht, Passau 2006, S. 104-108.

$21 \mathrm{Zu}$ dieser Doppelfunktion von Art. IV. Abs. 2 Satz 2 GrundG s. H. Küpper, Ungarns Verfassung vom 25. April 2011. Einführung - Übersetzung - Materialien, Frankfurt/M. 2012, S. 119.

22 Am Beispiel der Unterlassungsdelikte mit offenem Tatbestand $P$. Tapodi, A nyitott törvényi tényállású bủncselekmények mulasztásos változatának alkotmányos büntetőjogi vonatkozásai, különös tekintettel az Alkotmánybíróság gyakorlatára, Magyar Jog 2019 S. 165-179.

23 V. Kovács, in: A. Jakab (Hrsg.): Az Alkotmány kommentárja, 2 Bde., Budapest 2009, Bd. 1, $\S 31 / A$ Rn. 11-28. Diese Kommentierung betrifft zwar die Vorgängernorm in der alten Verfassung, kann aber mit wenig Änderungen auf das GrundG übertragen werden. 
weiß, spielt sie weder in der Verfassungs- noch in der sonstigen Rechtsprechung eine Rolle. Die Lehre bietet Paraphrasierungen ihres Wortlauts, sieht aber von einer inhaltlichen Auseinandersetzung ab. Die fundierteste Analyse dieser Verfassungsstelle beschränkt sich auf die Aussage, dass sie wohl von ähnlichen Vorschriften in den Verfassungen zahlreicher US-Bundesstaaten inspiriert ist und sich aus ihr „,keinerlei normativen Maßstäbe ableiten lassen“, nicht zuletzt wegen des unbeschränkten Gesetzesvorbehalts. ${ }^{24}$ Man kann Art. V. GrundG daher wohl als bloßes Symbol der erwähnten neuen ,trutzigeren“ Strafpolitik abtun.

Einige Besonderheiten hält das Grundgesetz für die - im Wesentlichen gescheiterte - strafrechtliche Aufarbeitung der Verbrechen der kommunistischen Diktatur bereit. In Reaktion auf die Auseinandersetzungen der 1990er Jahre um die Möglichkeit, bereits verjährte Regierungsverbrechen anzuklagen, erklärt es an mehreren Stellen die Unverjährbarkeit des seinerzeitigen Regimeunrechts. ${ }^{25}$ Allerdings kommt diese verfassungsrechtliche Klarstellung zu spät, denn von den Tätern des Regierungsunrechts von 1956/57 - und nur um dieses geht es - lebt kaum noch einer. ${ }^{26}$

Experimente am Menschen ohne dessen informierte Zustimmung, die genetische Rassenveredelung, die Kommerzialisierung des menschlichen Körpers und seiner Teile sowie das Klonen von Menschen sind von Verfassungs wegen verboten (Art. III. Abs. 2-3 GrundG). Dasselbe gilt für die Kinderarbeit (Art. XVIII. Abs. 1 GrundG) und den Müllimport (Art. XXI. Abs. 3 GrundG). Diese Vorschriften bilden die Grundlage der entsprechenden Straftatbestände im StGB, auch wenn die Verfassung selbst eine Bestrafung dieser Taten nicht verlangt, sondern nur ihr Verbot ausspricht.

In diesem Zusammenhang ist das verfassungsunmittelbare Verbot der Obdachlosigkeit zu erwähnen. In seiner ursprünglichen Form ermächtigte Art. XXII. Abs. 3 GrundG Gesetzgeber und kommunale Satzungsgeber, zum Schutz bestimmter Rechtsgüter „den lebensmittelpunkthaft sich verwirklichenden Aufenthalt im öffentlichen Raum“ zu verbieten. Diese Vorschrift war auf Druck der Bürgermeister in das GrundG aufgenommen worden, die eine Handhabe gegen Obdachlose haben wollten. Da dies nicht stets Erfolge zeitigte, sondern nach 2011 die sichtbare Obdachlosigkeit im Stadtbild v.a. der Großstädte noch zunahm, verschärfte die siebte Grundgesetzänderung v. 28.6.2018 den Art. XXII. Abs. 3 GrundG dahin gehend, dass nunmehr „,der lebensmittelpunkthafte Aufenthalt im öffentlichen Raum“ ohne Weiteres verboten ist. Laut Verfassungsgericht ist eine Sanktionierung der Obdachlosigkeit im öffentlichen Raum nur dann verfassungskonform, falls dem Obdachlosen zuvor eine Unterkunft angeboten worden ist und er diese ausgeschlagen hat. ${ }^{27}$

24 A. Jakab, Az új Alaptörvény keletkezése és gyakorlati következményei, Budapest 2011, Art. V., S. 208-209.

25 Präambel, Art. U) Abs. 1, 6-8 GrundG.

$26 \mathrm{Zu}$ den Diskussionen ab 1990 um die Möglichkeit, verjährte Staatsverbrechen zu bestrafen, s. Brunner, Sólyom (Fn. 19), S. 45-47; H. Küpper, Die rechtliche Aufarbeitung der kommunistischen Vergangenheit in Ungarn, in F.-C. Schroeder, H. Küpper (Hrsg.), Die rechtliche Aufarbeitung der kommunistischen Vergangenheit in Osteuropa, Frankfurt/M. 2009 S. 271-322 (304-308); Küpper, in: FS Schroeder (Fn. 10) S. 157; P. Sonnevend, Verjährung und völkerrechtliche Verbrechen in der Rechtsprechung des ungarischen Verfassungsgerichts, ZaöRV 1997 S. $185-228$.

27 VerfGE 19/2019. (VI. 18.) AB v. 18.6.2019, ergangen auf Vorlage eines Gerichts, dass die entsprechende Sanktionsnorm im OWiG für verfassungswidrig hielt. 2012 hatte das seiner- 
Die Strafgewalt der ordentlichen Gerichte hat ihre Verfassungsgrundlage in Art. 25 Abs. 2 S. 1 GrundG. Dies wird so verstanden, dass ausschließlich die ordentlichen Gerichte ,in Strafsachen“ entscheiden können. Anderen Staatsorganen oder gar nichtstaatlichen Rechtssubjekten steht keine Strafgewalt zu. Die Gerichte sind bei der Gesetzesauslegung nicht völlig frei, denn Art. 28 GrundG bindet ihre Spruchtätigkeit an bestimmte Kriterien, v.a. den Willen des historischen Gesetzgebers, wie er in den Regierungsbegründungen der Gesetzesvorlage zum Ausdruck kommt. Das Verfassungsgericht achtet darauf, dass die Gerichte sich hieran halten, und gibt der unterlegenen Prozesspartei das Recht, die fachgerichtliche Gesetzesauslegung durch das Verfassungsgericht auf ihre Regierungshörigkeit hin überprüfen zu lassen. ${ }^{28}$ Den staatlichen Strafanspruch macht ausschließlich die Staatsanwaltschaft geltend (Art. 29 Abs. 1 S. GrundG). ${ }^{29}$ Bei der Strafverfolgung ist die Polizei ihr Hilfsorgan (Art. 46 Abs. 1 S. 1 GrundG).

\section{Räumlicher und zeitlicher Geltungsbereich des StGB}

\section{Internationale Zuständigkeit}

$\S 3$ knüpft teilweise an das Staatsgebiet und teilweise an die Staatsangehörigkeit an. Danach erstreckt sich das StGB grundsätzlich auf alle Taten, die auf ungarischem Gebiet oder auf Schiffen oder Flugzeugen unter ungarischer Flagge begangen worden sind. Auf Auslandstaten findet das ungarische StGB Anwendung, wenn diese ein ungarischer Staatsbürger begangen hat.

Zudem kann ein ungarisches Opfer die Anwendbarkeit des ungarischen StGB begründen. Nach ungarischem Recht ist die Tat eines Nichtungarn im Ausland zu bestrafen, falls deren Opfer ein Ungar oder eine nach ungarischem Recht errichtete juristische Person oder nicht rechtsfähige Organisation ist. Auch Straftaten gegen den ungarischen Staat, die Ausländer im Ausland begehen, sind nach dem ungarischen StGB strafbar. Auf die Strafbarkeit nach Tatortrecht kommt es in diesen Fällen nicht an.

Schließlich ordnet $\S 3$ Abs. 2 Buchst. a) die Geltung des StGB für Auslandstaten von Ausländern an, falls die Tat sowohl nach ungarischem als auch nach Tatortrecht strafbar ist oder falls es sich um eine Straftat gegen die Menschlichkeit, ein Kriegsverbrechen oder sonst eine gemäß einem völkerrechtlichen Vertrag (auch) dem ungarischen Strafrecht unterliegende Tat handelt.

zeit noch nicht gleichgeschaltete Verfassungsgericht jedwede Sanktionierung von Obdachlosigkeit als Straftat oder Ordnungswidrigkeit als eine Verletzung der Menschenwürde angesehen: VerfGE 38/2012. (XI. 14.) AB v. 14.11.2012. Zur Sanktionierung der Obdachlosigkeit I. Ambrus, Az életvitelszerü közterületi tartózkodás szabályainak megsértése szabálysértéséről, Közjogi Szemle 2018/4 S. 1-7; M. Gkresta, Social Control in Times of Crisis: Criminalizing Homelessness in Budapest, Der Donauraum 2014 S. 537-554.

28 VerfGE 23/2018. (XII. 28.) AB v. 28.12.2018, hierzu s. OER 2019 S. 289-290.

29 Hiervon weicht die StPO ab. Bestimmte leichte Delikte werden grundsätzlich von der Staatsanwaltschaft gar nicht, sondern nur durch den Verletzten verfolgt, der hierbei als sog. „Privatankläger“ auftritt, und der Verletzte kann als sog. „Ersatzprivatankläger“ die Anklage vertreten, falls bei einem Offizialdelikt die Staatsanwaltschaft die Anklage ablehnt. 
Anklagen gegen Ausländer wegen im Ausland begangener Taten obliegen dem Generalstaatsanwalt (§ 3 Abs. 3).

\section{Intertemporale Aspekte}

Gemäß $§ 2$ findet das neue Recht auf alle Taten Anwendung, die nach seinem Inkrafttreten verübt worden sind. Den Übergang vom alten zum neuen materiellen Recht regelt im Übrigen das EG-StGB. Hierbei gilt die Grundregel, dass in Fällen, in denen das neue StGB milder ist als das alte, v. a. in den Fällen, in denen das neue Recht eine ehemalige Straftat nur noch als Ordnungswidrigkeit sanktioniert, auch eine noch laufende Strafvollstreckung an das mildere Recht anzupassen ist (§2 Abs. 2-3 StGB i.V.m. $\S \S 1-3$ EG-StGB). Obwohl diese Regel einfach erscheint, hat der Übergang vom alten zum neuen Recht eine recht umfangreiche höchstrichterliche Rechtsprechung ausgelöst. In deren Mittelpunkt stehen die Anwendbarkeit welchen Rechts auf Dauerstraftaten und auf von einer Gesamtstrafe u. ä. erfasste Zeiträume sowie die Einzelheiten der Rückwirkung des milderen Rechts.

Insbesondere die Gesamtstrafenbildung sorgte für Rechtsunsicherheit. Ursprünglich sah $\S 3$ EG-StGB die Anwendbarkeit des neuen Rechts grundsätzlich dann vor, wenn mindestens eines der Urteile, die in eine Gesamtstrafe zusammengefasst werden sollten, nach dem Inkrafttreten des StGB rechtskräftig geworden ist. Aufgrund einer Verfassungsbeschwerde hob das Verfassungsgericht diese Bestimmung auf, weil sie angesichts der Tatsache, dass das neue StGB in mancher Hinsicht schärfer als das alte ist, das Verbot rückwirkender verschärfender Strafvorschriften verletzt. ${ }^{30} \mathrm{Um}$ die daraufhin divergierende Rechtsprechung zu vereinheitlichen, erließ der Rechtseinheitlichkeitssenat für Strafsachen der Kurie (wie das oberste Gericht seit 2012 wieder genannt wird) am 3. Juni 2019 den Rechtseinheitlichkeitsbeschluss in Strafsachen 2/2019. BJE, der den Zeitpunkt für maßgeblich erklärt, an dem die Möglichkeit einer Gesamtstrafenbildung erstmals entsteht: Liegt dieser Zeitpunkt vor dem 1. Juli 2013, ist altes Recht anwendbar, ansonsten das neue StGB. Wegen verbotener Rückwirkung hob das Verfassungsgericht in einem konkreten Normenkontrollverfahren diesen Rechtseinheitlichkeitsbeschluss als verfassungswidrig auf. ${ }^{31}$ Ein neuer Rechtseinheitlichkeitsbeschluss zu diesem Thema ist bislang noch nicht ergangen, sodass unklar ist, was gilt. Sicher ist, dass die Rechtsprechung eine einheitlich abzuurteilende Tatmehrheit, deren Taten teils vor und teils nach dem Inkrafttreten des neuen StGB begangen wurden, in ihrer Gesamtheit dem neuen Strafrecht unterstellt. ${ }^{32} \mathrm{Ob}$ das mit dem strafrechtlichen Rückwirkungsverbot vereinbar ist, muss noch geklärt werden.

30 VerfGE 10/2018. (VII. 18.) AB v. 18.7.2018.

31 Rechtseinheitlichkeitsbeschluss in Strafsachen 2/2019. BJE, Kúriai Döntések (Entscheidungssammlung der Kurie, abgekürzt: KD) 2019/9, aufgehoben durch VerfGE 1/2020. (I. 2.) $A B$ v. 2.1.2020. Rechtseinheitlichkeitsbeschlüsse sind quasinormative Entscheidungen der Kurie, in denen diese der nachgeordneten Gerichtsbarkeit verbindlich die Auslegung einer konkreten Gesetzesstelle vorgibt, um eine divergierende Rechtspraxis zusammenzuführen. Näher zum Rechtseinheitlichkeitsbeschluss $H$. Küpper, Einführung in das ungarische Recht, München, Wien 2011, S. 10, 18.

32 Kurie, KD 2019 Nr. 153, Leitsatz II. 


\section{Allgemeiner Teil}

Das Kapitel über die Strafzumessung wird mit einer Definition des Strafzwecks eingeleitet. Da diese Norm für das gesamte StGB von Bedeutung ist, sei sie an dieser Stelle übersetzt: „§ 79. Zweck der Bestrafung ist es, im Interesse des Schutzes der Gesellschaft dem vorzubeugen, dass weder der Täter noch ein anderer eine Straftat begeht." Das StGB ist mithin der Spezial- und der Generalprävention, nicht aber der Vergeltung verpflichtet.

\section{Die Tat}

Das mit „Die strafrechtliche Verantwortlichkeit“ überschriebene Kap. III enthält die grundlegenden Differenzierungen der Straftaten. Laut $\S 4$ setzt eine Strafbarkeit die Definition als Straftat im StGB (Tatbestandsmäßigkeit), die vorsätzliche oder fahrlässige Tatbegehung und die Sozialgefährlichkeit voraus. Die Strafbarkeit entfällt trotz Tatbestandsmäßigkeit, wenn eine Rechtsvorschrift die Tat erlaubt (§24). Ungeregelt ist die Strafbarkeit des Handelns im erlaubten Risiko.

Während Vorsatztaten stets strafbar sind, muss für eine Fahrlässigkeitstat deren Strafbarkeit konkret angeordnet sein. Vorsätzlich handelt gemäß $§ 7$, wer die Folgen der Tat will oder sich mit ihnen abfindet, während Fahrlässigkeit gemäß $\S 8$ vorliegt, wenn der Täter die Folgen der Tat nicht sieht, weil er die von ihm erwartbare Umsicht unterlässt, oder er die Folgen zwar sieht, aber leichtfertig auf ihr Ausbleiben vertraut. Bei erfolgsqualifizierten Delikten reicht es grundsätzlich aus, wenn hinsichtlich des Erfolgs Fahrlässigkeit festgestellt werden kann (§9).

An der sozialistischen Kategorie der Sozialgefährlichkeit hält das neue StGB ausdrücklich fest. § 4 Abs. 2 definiert sie als „Tätigkeit oder Unterlassung, die die Person eines Anderen oder seine Rechte beziehungsweise die gesellschaftliche, wirtschaftliche oder staatliche Ordnung gemäß Ungarns Grundgesetz verletzt oder gefährdet". Warum diese aus dem sozialistischen Strafrecht stammende Kategorie weiter mitgeschleppt wird, erklärt die Regierungsbegründung zur Gesetzesvorlage nicht. In der Praxis spielt die Sozialgefährlichkeit eine untergeordnete Rolle ${ }^{33}$ und dient am ehesten zur Verfahrenseinstellung bei Bagatelldelikten.

$\S 5$ unterscheidet zwischen Verbrechen und Vergehen. Die Grenze liegt bei einer Mindeststrafe von zwei Jahren Freiheitsentzug für ein Vorsatzdelikt. Straftaten unterhalb dieser Grenze sowie alle Fahrlässigkeitstaten sind Vergehen. Diese Unterscheidung hat nur im materiellen Strafrecht eine Bedeutung, während das Strafverfahrensrecht einheitlich von Straftaten spricht.

Wer eine vorsätzliche Straftat beginnt, aber nicht beendet, wird wegen Versuchs bestraft (§ 10). Das Strafmaß richtet sich nach der versuchten Tat. Bei einem untauglichen Versuch kann die Strafe unbeschränkt gemildert oder ganz von ihr abgesehen werden. Die Versuchsstrafbarkeit entfällt zwingend, wenn der Täter während der Tat-

33 Z. Á. Bangó, A Kúria harmadfokú döntése a megbízhatósági vizsgálat keretében elkövetett korrupciós büncselekményről. A megbízhatósági vizsgálat és a társadalomra veszélyesség egyes összefüggései, Jogesetek Magyarázata 2018/2. 
begehung freiwillig auf die Vollendung verzichtet oder den Eintritt der Folge freiwillig abwendet. Im Gegensatz zum Versuch, der bei Vorsatztaten stets strafbar ist, wird die Vorbereitung gemäß $\S 11$ nur bestraft, wenn das StGB dies gesondert anordnet. ${ }^{34}$ Vorbereitungstäter $^{35}$ ist, wer Voraussetzungen, die die Haupttat ermöglichen oder erleichtern, schafft, zur Tatbegehung auffordert, sie anbietet, sich dazu verpflichtet oder eine gemeinsame Tatbegehung vereinbart.

Unklar bleibt die Abgrenzung zwischen der Legaldefinition der Tatvorbereitung in $\S 11$ Abs. 1 und den Tatformen der Anstiftung und der Beihilfe, die gemäß $\S 14$ in dem Strafrahmen der Haupttat zu bestrafen sind. Beim Täter unterscheidet $\S 13$ zwischen dem Täter, der die Tatbestandsmerkmale selbst verwirklicht, dem mittelbaren Täter, der sich zur Tatbegehung einer schuldunfähigen oder in einem Irrtum befindlichen Person bedient, und dem Mittäter, der zusammen mit anderen Mittätern in gegenseitigem Wissen voneinander die Merkmale einer vorsätzlichen Tat erfüllt. Die Regel des alten Rechts, dass ein Beteiligter auch dann verurteilt werden kann, wenn der Täter unbekannt ist, wurde zwar nicht in das neue StGB übernommen, jedoch urteilt die Praxis weiterhin dementsprechend. ${ }^{36}$

Juristische Personen sind ein selbstständiges Zurechnungssubjekt strafrechtlich relevanter Taten. Der Regelungsort ist nicht das StGB, sondern ein separates Gesetz, das sowohl die materiell-rechtlichen als auch die Verfahrensaspekte regelt (JPersStrG). ${ }^{37}$ Danach ist eine juristische Person strafrechtlich verantwortlich, wenn ein Organwalter, ein gesetzlicher oder organschaftlicher Vertreter, aber auch ein Arbeitnehmer Vorsatztaten zur Bereicherung der juristischen Person oder unter ihrer Ausnutzung begehen oder aber wenn eine dritte Person eine solche Tat begeht und ein Organwalter, Vertreter oder Arbeitnehmer der juristischen Person davon weiß (§ 2 JPersStrG). Während in den ersten Jahren nach dem Erlass des JPersStrG kaum Verfahren gegen juristische Personen eingeleitet wurden, gewinnt diese Möglichkeit im Steuerstrafrecht zunehmend an Bedeutung. ${ }^{38}$

Der Abgrenzung von Tatmehrheit und fortgesetzter Tat dient $\S 6$, wonach mehrere Handlungen aufgrund eines einheitlichen Entschlusses gegen denselben Verletzten innerhalb kurzer Zeit eine fortgesetzte Tat bilden. Bei Delikten mit komplexem Tatablauf kann die Abgrenzung zwischen einheitlicher und fortgesetzter Tat problematisch

34 So z. B. im BT in $\S 160$ Abs. 3 für die Vorbereitung einer Tötung oder neuerdings in $\S 322 / \mathrm{A}$ Abs. 4 für die Vorbereitung der Verhinderung einer seuchenrechtlichen Maßnahme.

35 Die Vorbereitung kann nur in Täterschaft, aber nicht in Teilnahme begangen werden: Kurie, KD 2020 Nr. 32 Leitsatz II.

36 Gerichtstafel Debrecen, AZ.: DIT Bf.513/2013/33: Wenn vier Personen an einer Tötung beteiligt sind, aber nicht festzustellen ist, wer von den vieren die Tötungshandlung begangen hat, können alle vier wegen Beihilfe verurteilt werden. Hierzu kritisch aus der Sicht der Akzessorietät von Anstiftung und Beihilfe Á. Mészáros, A Debreceni Ítélőtábla döntése emberölési ügyben, Jogesetek Magyarázata 2016/1-2 S. 45-56.

Gerichtstafeln (alternative Übersetzung: Tafelgerichte) sind die zweithöchste Ebene der vierstufigen Justiz.

37 Gesetz 2001:CIV über die strafrechtlichen Maßnahmen, die gegenüber juristischen Personen verhängt werden können, v. 24.12.2001, MK 2001 Nr. 153 S. 11428, in deutscher Übersetzung abgedruckt in Institut für Ostrecht München (Hrsg.): Handbuch Wirtschaft und Recht in Osteuropa, Loseblatt, München, Dokument UNG 325.

38 D. Fehér, J. Szax, C. Melicher, in: WiRO-Handbuch (Fn. 36), UNG D.XI Rn. 158-160. 
sein, was letztlich nur durch richterliche Wertung im Einzelfall lösbar ist. ${ }^{39}$ Im Übrigen stehen mehrere Handlungen in Tatmehrheit.

\section{Strafausschließungs-, -milderungs- und -aufhebungsgründe}

Die Strafmündigkeit ist in $\S 16$ differenziert geregelt. Grundsätzlich tritt sie mit der Vollendung des 14. Lebensjahres ein. Bei bestimmten Katalogstraftaten gilt eine Grenze von 12 Jahren, so bei verschiedenen Tötungs- und Körperverletzungsdelikten, Terrorismus und der Ausplünderung Wehrloser. Bei 12- bis 14-jährigen muss die Einsichtsfähigkeit im Einzelfall festgestellt werden. ${ }^{40}$ Die Strafmündigkeitsgrenze von 12 Jahren ist nicht ohne historische Vorläufer: Der Csemegi-Kodex verwendete sie, und erst das StGB von 1961 hob die Altersgrenze ausnahmslos auf 14 Jahre an. ${ }^{41}$ Die partielle Absenkung der Strafmündigkeit ist eine der im Schrifttum umstrittensten Neuerungen.

Wer geistig nicht in der Lage ist, die Folgen seiner Tat einzusehen, kann grundsätzlich nicht bestraft werden. Ist die Einsichtsfähigkeit nur beschränkt, kann das Gericht die Strafe unbegrenzt mildern oder ganz vor ihr absehen (§17). Wer sich allerdings selbst durch Alkohol oder Gifte in einen Zustand der Unzurechnungsfähigkeit bringt, kann sich auf diesen Strafausschließungs- oder -milderungsgrund nicht berufen.

Auch Zwang und Drohung führen je nach Intensität zum Ausschluss der Strafbarkeit oder zu einer unbegrenzten Strafmilderungsmöglichkeit (§ 19). Der Irrtum zum Zeitpunkt der Tatbegehung schließt die Strafbarkeit aus, außer er beruht auf Fahrlässigkeit (§ 20). ${ }^{42}$ Die Vorschrift differenziert nicht zwischen Tatsachen- und Verbotsirrtum. Eine spezielle Form des Verbotsirrtums regelt $\S 20$ Abs. 2: Ein Irrtum über die Sozialgefährlichkeit der Tat lässt die Strafbarkeit nur entfallen, wenn der Täter einen guten Grund zu der irrtümlichen Annahme der fehlenden Sozialgefährlichkeit hatte. ${ }^{43}$

Ausführlich regeln $\S \S 21-23$ Notwehr, Nothilfe und Notstand. Im Gegensatz zu Art. V. GrundG umfassen diese Vorschriften auch die Hilfe bei einem Angriff auf die Rechtsgüter eines anderen. ${ }^{44}$ Notwehr und Nothilfe zur Abwehr eines drohenden An-

39 So für die Unterschlagung der Rechtseinheitlichkeitsbeschluss in Strafsachen 1/2016. BJE.

40 Innerhalb der unter 18-jährigen Täter machen die 12- bis 14-jährigen über die Hälfte aus; Statistiken liefert M. Tóth, Az új Btk. bölcsőjénél, Magyar Jog 2013 S. 525-534 (530-531). Die Verurteilungszahlen sind jedoch minimal: A. Pallagi, Büntethető gyermekkorúak, Pro Futuro 2014/1 S. 97-111; Tóth (Fn. 12), S. 18-19.

41 Á. Balogh, L. Bozsánovics, A büntethetőség alsó életkori határának történeti előzményei, Jura 2017/1 S. 11-17.

42 Kurie, KD 2018 Nr. 216, Leitsatz II: Wer auf anwaltlichen Rat hin eine Straftat begeht, befindet sich in einem strafausschließenden Irrtum.

43 Kurie, Grundlagenentscheidung in Strafsachen EBH 2019. B.12: Die Übermalung von Wahlplakaten ist eine Sachbeschädigung, und die Annahme, dass dies durch die Meinungsfreiheit gedeckt sei, lässt die Sozialgefährlichkeit nicht entfallen.

44 Trotz dieser Abweichung ist Art. V. GrundG der Ausgangspunkt des strafrechtlichen Notstandsrechts: Kurie, Rechtseinheitlichkeitsbeschluss in Strafsachen 4/2013. BJE. Zu diesem Rechtseinheitlichkeitsbeschluss $A$. Gál, A Kúria jogegységi határozata a jogos védelemröl, Jogesetek Magyarázata 2014/3 S. 23-35. 
griffs lassen die Strafe entfallen, falls das Mittel das mildeste und nicht zur Auslöschung eines Lebens geeignet war. Stärker dürfen die Verteidigungsmittel bei einem laufenden Angriff gegen sich selbst, einen anderen oder öffentliche Interessen sein, wobei unter bestimmten, genau definierten Voraussetzungen auch lebensgefährliche Verteidigungsmittel angewendet werden dürfen, was gegenüber dem alten Recht eine deutliche Ausweitung der Notwehr darstellt. ${ }^{45}$ Wer im Eifer des Gefechts die Grenzen der Notwehr oder -hilfe überschreitet, ist nicht strafbar. Im Notstand darf das Verteidigungsmittel keinen größeren Schaden verursachen als die Tat, die es abwehren soll.

Die Strafbarkeit entfällt nachträglich durch den Tod des Täters, Verjährung, Begnadigung, tätige Reue und sonstige gesetzliche Gründe. Differenziert regeln $\S \S 26-28$ die Verjährung, die mit der Vollendung der Tat beginnt; Sonderregeln gelten für Versuche, Vorbereitungshandlungen, Unterlassungs- und Dauerdelikte. ${ }^{46}$ Die allgemeine Verjährungsfrist ist mit der Höchstdauer der angedrohten Strafe identisch, beträgt aber mindestens fünf Jahre. Korruptionstaten verjähren nach zwölf Jahren, und die Verjährung ist bei Verbrechen gegen die Menschlichkeit, Kriegsverbrechen, Sexualdelikten gegenüber Minderjährigen sowie dann ausgeschlossen, wenn die Straftat auch mit lebenslanger Freiheitsstrafe bestraft werden kann.

Tätige Reue ist nur bei bestimmten Delikten möglich. Eine vom Opfer dem Grunde und dem Umfang nach akzeptierte Wiedergutmachung lässt die Strafbarkeit entfallen. Weniger hohe Hürden gelten für die tätige Reue bei weniger gravierenden Straftaten. Tätige Reue ist bei Rückfalltätern, Bandentaten ${ }^{47}$ und Tötungsdelikten ausgeschlossen (§ 29).

Ihrer Natur nach strafprozessualer Natur sind die Strafverfolgungshindernisse des Fehlens des Strafantrags oder der Anzeige ( $\S 30-32)$. Wo das StGB die Bestrafung von dem Vorliegen eines Strafantrags des Verletzten oder einer Anzeige des dazu Berechtigten abhängig macht, ist eine Strafverfolgung ausgeschlossen, wenn diese Voraussetzung fehlt.

\section{Sanktionen}

Das Sanktionensystem besteht aus Strafen und Maßnahmen. Nur die Strafen sind eine Reaktion unmittelbar auf die Tat, während die Maßnahmen anlässlich der Tat angeordnet werden. ${ }^{48}$ Die frühere Unterscheidung zwischen Haupt- und Nebenstrafen ist fast komplett entfallen: Die Strafarten in $\S 33$ sind alle Hauptstrafen und können als solche grundsätzlich frei miteinander kombiniert werden. Als einzige Nebenstrafe hält $\S 33$ Abs. 2 das Verbot der Teilnahme an den öffentlichen Angelegenheiten aufrecht. Es setzt gemäß $\S \S 61-62$ voraus, dass der Täter wegen einer Vorsatztat zu einer zu

45 Zur teils heftigen Kritik hieran Tóth (Fn. 39), S. 531-532.

46 Beim „Besitz von Rauschgift“ beginnt die Verjährung erst, wenn der Täter das Rauschgift nicht mehr in seinem Besitz hat: Kurie, KD 2019 Nr. 189.

47 Für die Mitgliedschaft in einer Bande reicht bereits eine recht lose Verbindung zu den kriminellen Strukturen. Auch wer sich auf die reine Organisation beschränkt, haftet strafrechtlich voll für die begangenen Straftaten: Kurie, KD 2019 Nr. 259.

48 B. Busch (Hrsg.), Büntetőjog I, Budapest 2012, S. 388-391. In deutscher Sprache, wenn auch zum alten Recht Tóth (Fn. 20), S. 95-96, 123-130. 
vollstreckenden Freiheitsstrafe verurteilt wurde und der Teilnahme an öffentlichen Angelegenheiten unwürdig ist. Theoretisch sind beide Voraussetzungen unabhängig voneinander zu prüfen, aber die Praxis ist von einem Automatismus geprägt: Wer ins Gefängnis muss, gilt per se als unwürdig. Das Verbot umfasst das Wahlrecht, das Bekleiden öffentlicher Ämter, die Verleihung in- und ausländischer Ehrungen und militärischer Ränge sowie die Leitung privatrechtlicher Vereine.

Im Mittelpunkt des Strafensystems steht die Freiheitsstrafe, die entweder zeitig oder lebenslang sein kann (§34). Eine zeitige Freiheitsstrafe dauert zwischen drei Monaten ${ }^{49}$ und 20 Jahren; bei Bandentätern, mehrfachen Rückfalltätern und bei der Tateinheits- und Gesamtstrafe beträgt die Obergrenze 25 Jahre. Sie wird je nach Art der Straftat und der Eigenschaft als Rückfalltäter in Arrestanstalten, Gefängnissen oder Zuchthäusern verbüßt, ${ }^{50}$ worüber das Gericht im Strafurteil zu befinden hat. Ebenso muss das Gericht im Strafurteil entscheiden, ob eine vorzeitige Haftentlassung möglich ist und wenn ja, nach welcher Zeit. Die gesetzliche Mindesthaftzeit beträgt zwei Drittel und bei Rückfalltätern drei Viertel des Strafausspruchs. Nicht möglich ist eine vorzeitige Haftentlassung für Mehrfachrückfalltäter von schweren oder gewalttätigen Straftaten, Bandentäter oder Täter, die während der Bewährungszeit neue Straftaten begehen ( $§ 38-40)$.

Die lebenslange Freiheitsstrafe ist das Flaggschiff der angeblich strengen Kriminalpolitik der Fidesz-Regierung, weshalb sie auch im GrundG Erwähnung findet. Nach altem Recht wurden lebenslang Verurteilte regelmäßig nach 20-25 Jahren aus der Haft entlassen, während nunmehr lebenslang tatsächlich lebenslang dauern (können) soll. Für dieses Kernstück ihrer kriminalpolitischen Propaganda nahm die Fidesz-Regierung sogar mehrere Verurteilungen durch den EGMR in Kauf, der in dem Fehlen eines rechtlichen Mechanismus, mit dem der Verurteilte eine vorzeitige Haftentlassung beantragen kann, eine unmenschliche Strafe sah. ${ }^{51}$ Letztlich geht es um Symbole, da ungarische Gerichte eine tatsächlich lebenslange Freiheitsstrafe kaum gegenüber Tätern anordnen, die jünger als 40 Jahre sind, ${ }^{52}$ was die praktische Bedeutung der Haftentlassungsmöglichkeiten nach 25 Jahren Haft und mehr relativiert. Der BT sieht die lebenslange Freiheitsstrafe immer nur als eine Alternative neben zeitigen Freiheitsstrafen vor. Zu lebenslanger Freiheitsstrafe kann nur verurteilt werden, wer zur Zeit der Tat das 20. Lebensjahr vollendet hat; falls mehrere Taten gemeinsam abgeurteilt werden, muss die Altersgrenze bei allen Einzeltaten vorliegen. ${ }^{53}$ Die Strafe wird im Zuchthaus verbüßt (§41). Auch bei der lebenslangen Freiheitsstrafe hat das

49 Zur ungarischen Diskussion über Sinn und Unsinn extrem kurzer Freiheitsstrafen F. Nagy, A szankciórendszer, Jogtudományi Közlöny 2015 S. 1-15 (2-3).

$50 \mathrm{Zu}$ dieser Unterscheidung s. Küpper (Fn. 31), S. 285. Kritisch zu der kasuistischen und daher unübersichtlichen Regelung, wann Zuchthaus anzuordnen ist, Nagy (Fn. 48), S. 3.

51 EGMR, László Magyar./. Ungarn, 20.5.2014, AZ.: 73593/10, T.P. und A.T../. Ungarn, 4.10.2016, AZ.: 37871/14 und 73986/14, dazu OER 2014 S. 516-517, 2017 S. 144; $H$. Küpper, Die Bedeutung der EMRK in Demokratien im Umbruch, in: M. Pöschl, E. Wiederin (Hrsg.), Demokratie und Europäische Menschenrechtskonvention, Wien 2019, S. 171-172; Nagy (Fn. 48), S. 3-6; P. Ruzsonyi, Life Sentence Without the Possibility of Parole. „We Do not Allow Them to Live, We Do not Let Them Die“, Aarms 2018 S. 111-126.

52 L. Balla: A életfogytig tartó szabadságvesztés büntetéskiszabási gyakorlata, Magyar Rendészet 2014/6 S. 43-68.

53 Kurie, Stellungnahme des Strafrechtlichen Kollegiums 5/2013. (XII. 11.) BK v. 11.12.2013. 
Gericht im Strafurteil über die Möglichkeit der vorzeitigen Haftentlassung zu entscheiden; nur bei bestimmten Taten der Schwerstkriminalität wie Terrorismus, bestimmte vorsätzliche Tötungen oder schwerste Delikte mit Todesfolge darf das Gericht die vorzeitige Haftentlassung komplett ausschließen. Es muss sie bei gewalttätigen mehrfachen Wiederholungs- und bei Bandentätern ausschließen. Wenn das Gericht die vorzeitige Haftentlassung ermöglicht, kann es dies frühestens nach 25 und spätestens nach 40 Haftjahren tun; die Bewährungsfrist beträgt 15 Jahre ( $\S 42-45)$.

Aus dem OWiG übernommen wurde der Arrest. Der strafrechtliche Arrest ist in Tagen zu bestimmen und kann zwischen fünf und 90 Tagen dauern. Er wird in einer Strafvollzugsanstalt verbüßt (§46). Statt Arrest oder zusätzlich dazu können Arbeit im öffentlichen Interesse, Geldstrafe, Berufs- und Fahrverbot, Orts- und/oder Stadionverbot und/oder Ausweisung verhängt werden (§33 Abs. 5). Die Kombination von Freiheitsstrafe und Arrest hingegen ist unzulässig. Die Verurteilungen zu Strafarrest nehmen seit 2013 stetig zu. Andere Formen der Freiheitsbeschränkung wie Hausarrest oder Fußfesseln sieht das Strafverfahrensrecht als Alternativen zur Untersuchungshaft vor, während sie als mögliche Strafarten bestenfalls akademisch diskutiert werden.

Eine in Ungarn traditionelle Strafart ist die Arbeit im öffentlichen Interesse (§§ 47-49), die in Stunden bemessen wird und zwischen 48 und 312 Stunden dauern kann. Sie ist regelmäßig einmal wöchentlich an einem arbeitsfreien Tag ohne Vergütung durchzuführen. Ihre Art wird im Strafurteil festgelegt. Wenn der Verurteilte sich der Arbeit entzieht oder im Zeitraum der Arbeit erneut straffällig wird, wird sie in eine Freiheitsstrafe umgewandelt. Im Übrigen dürfen Freiheitsstrafe und Arbeit im öffentlichen Interesse nicht kombiniert werden. Der Gesetzgeber sieht den Sinn der Arbeit im öffentlichen Interesse in der Möglichkeit, dass der Verurteilte seinen Schaden wiedergutmacht, und die Regierung wünscht sich in ihrer offiziellen Begründung zur Gesetzesvorlage, dass die Gerichte häufiger von dieser Strafart Gebrauch machen. ${ }^{54}$

Die Geldstrafe beträgt 30 bis 540 Tagessätze, deren Höhe sich nach den Einkommens- und Vermögensverhältnissen des Täters zu richten hat ( $\S 50-51)$. Sie ist bei Taten zur Vorteilserlangung neben der Freiheitsstrafe obligatorisch. Ansonsten kann die Geldstrafe frei mit anderen Strafarten außer mit der lebenslangen Freiheitsstrafe und der Ausweisung kombiniert werden. Zahlt der Verurteilte nicht oder nicht rechtzeitig, wird die Geld- in eine Freiheitsstrafe umgewandelt, für die die Mindestdauer von drei Monaten ausdrücklich nicht gilt. Zudem hat das neue BGB von 2013 bei der Haftung für Persönlichkeitsrechtsverletzungen das Schmerzensgeld eingeführt, dessen Zweck von der Rechtsprechung ausdrücklich auch als „privatrechtliche Bestrafung“ mit Präventivcharakter definiert wird, was auch bei der Höhe des Schmerzensgeldes zu berücksichtigen ist. ${ }^{55}$

$\mathrm{Zu}$ den weiteren Strafarten zählt das Berufsverbot, das befristet zwischen einem und zehn Jahren oder auch dauerhaft zulässig ist, wenn die Straftat berufliche Standards verletzt oder unter Ausnutzung der beruflichen Stellung erfolgt ist ( $\S 52-54$ ). Für ein dauerhaftes Berufsverbot muss das Strafgericht die Ungeeignetheit oder Unwürdigkeit des Täters für den gegebenen Beruf feststellen. Bei Handelsgesellschaften

54 Busch (Fn. 47), S. 417-422; Nagy (Fn. 48), S. 7-8.

55 Kurie, KD 2019 Nr. 268. Der immaterielle Schadensersatz nach altem Recht diente nur dem Nachteilsausgleich. 
prüft das Firmengericht durch Regelabfrage im Strafregister, ob Organwalter, Manager etc. einem Berufsverbot unterliegen. Wer wegen eines Sexualdelikts gegen Minderjährige verurteilt wird, dem ist dauerhaft jede Berufstätigkeit zu verbieten, die ihn mit Minderjährigen in Kontakt bringt. Bei Delikten mit Verkehrsbezug ist ein Fahrverbot von einem Monat bis zu zehn Jahren oder, falls der Täter als Fahrer ungeeignet ist, dauerhaft zulässig ( $§ 55-56) .{ }^{56}$ Bei bestimmten Straftaten wie der Belästigung („Stalking“, $\S \S 222$ i.V.m. 230) oder Umweltdelikten ( $\$ 253)$ kann das Gericht ein Ortsverbot verhängen, das dem Täter den Aufenthalt in einer oder mehreren Gemeinden oder einem Landesteil verbietet (§ 57). Das Ortsverbot kann von einem Jahr bis zu fünf Jahren dauern und setzt voraus, dass der Aufenthalt des Täters an dem gegebenen Ort öffentliche Interessen verletzt. Im alten Recht war das Ortsverbot keine Haupt-, sondern eine Nebenstrafe. Die Hochstufung begründet die Regierung damit, dass so das Ortsverbot als Hauptstrafe auch selbstständig verhängt werden könne. Eine Sonderform des Ortsverbots ist das Verbot des Besuchs von Sportveranstaltungen $(\S 58)$, das das Gericht wegen Taten im Zusammenhang mit Sportereignissen für die Dauer von einem bis zu fünf Jahren verhängen kann. Im StGB ist diese für Ordnungswidrigkeiten seit langem bekannte Verselbstständigung des sportbezogenen Ortsverbots eine Neuerung. Ausländische Täter, deren Aufenthalt im Land nicht erwünscht ist, können für eine Frist von einem bis zu zehn Jahren oder auch dauerhaft ausgewiesen werden. Eine Ausweisung anerkannter Asylberechtigter ist nicht möglich, bei EU- und EWG-Bürgern, langansässigen Ausländern sowie Tätern mit ungarischen Familienangehörigen muss eine entsprechend schwere Tat vorliegen ( $\S 59-60$ ). $\S 33$ Abs. 6 Buchst. b) verbietet die Kombination von Ausweisung und Arbeit im öffentlichen Interesse oder Geldstrafe.

Neben den Strafen sehen $\S \S 63-78$ eine Reihe von Maßnahmen vor. Erwähnenswert sind die Rüge für Bagatelldelikte; das Absehen von einer Freiheitsstrafe auf Bewährung, was v.a. für Ersttäter vorgesehen ist; die Wiedergutmachungsarbeit, die ggf. unter Aufsicht eines Bewährungshelfers zum Aufschub und zur Streichung einer verhängten Freiheitsstrafe führt; die Zwangsheilbehandlung, die gegenüber Unzurechnungsfähigen angeordnet werden kann, falls eine Wiederholung zu befürchten ist. Von Bedeutung sind die vermögensbezogenen Maßnahmen der Einziehung der Mittel zur und der Gewinne aus der Straftat und die Vermögenseinziehung, die generell der Gewinnabschöpfung dient ${ }^{57}$ und bei bestimmten Kriminalitätsformen von der widerleglichen gesetzlichen Vermutung ausgeht, dass das gesamte Tätervermögen kriminell erworben wurde.

Nach ungarischer Dogmatik gehören auch die Kriminalsanktionen gegen juristische Personen zu den Maßnahmen, wie $\S 63$ Abs. 1 Buchst. i) klarstellt. Gegen eine juristische Person erlaubt $\S 3$ JPersStrG die folgenden Maßnahmen: Auflösung, Beschränkung der Tätigkeit und Geldbuße. Die Auflösung ist nur selbstständig anwend-

56 Jede Tatbeteiligung als Täter oder Teilnehmer an einem verkehrsbezogenen Delikt reicht aus, es ist nicht notwendig, dass der Betreffende selbst gefahren ist, um ihn mit einem Fahrverbot belegen zu können: Kurie, KD 2020 Nr. 2.

57 Rechtseinheitlichkeitsbeschluss in Strafsachen 2/2020. BJE: Unzulässig ist die Einziehung von Vermögen, das an den Verletzten herauszugeben ist, zulässig hingegen die Einziehung des Vermögens, um das der Täter im Zusammenhang mit dem tatgegenständlichen Vermögensgegenstand bereichert ist, d. h. auch Surrogate können eingezogen werden. 
bar, während Tätigkeitsbeschränkungen und Geldbußen jede für sich oder auch in Kombination miteinander verhängt werden können.

\section{Strafzumessung}

Bei der Strafzumessung soll das Gericht die Strafzwecke des $§ 79$, d. h. die Spezialund die Generalprävention, sowie die objektive Schwere der Tat, die Sozialgefährlichkeit des Täters, den Grad der Schuld sowie weitere mildernde und verschärfende Umstände berücksichtigen. In der Strafzumessung kommen mithin auch Vergeltungsaspekte zum Tragen. Ausgangspunkt für den „Normalfall“ ist bei Freiheitsstrafen die mathematische Mitte zwischen der Mindest- und der Höchststrafe ( $§ 80)$, was bereits der Csemegi-Kodex so vorsah. ${ }^{58}$ Sondervorschriften gelten für die einheitliche Strafe bei Tatmehrheit, für die Milderung der Strafe, die im Einzelfall auch unterhalb der Mindeststrafandrohung möglich ist, und für die Gesamtstrafe. Kürzere Freiheitsstrafen können zur Bewährung ausgesetzt werden, müssen aber nicht. Da die Regeln Teil des materiellen Strafrechts sind, befindet der Tatrichter in seinem Strafurteil auch über die Bewährung. Keine Bewährung erhalten mehrfache Wiederholungs- und Bandentäter sowie wer in der Bewährungszeit erneut straffällig wird (§§ 85-88). Für Strafen und Maßnahmen gegenüber Minderjährigen rücken $\S \S 105-126$ den Erziehungsgedanken in den Vordergrund; dem entspricht die Erweiterung des Arsenals möglicher Sanktionen um die Erziehung in einer Besserungsanstalt. Spezielle Sanktionen kennt auch das Militärstrafrecht in $\S \S 127-141$.

Bei Rückfalltätern v.a. von Gewaltdelikten erhöht sich das Strafobermaß um die Hälfte, ${ }^{59}$ bei Bandentätern auf das Doppelte, aber in beiden Fällen höchstens auf 25 Jahre Freiheitsstrafe ( $§ 89-90)$. Diese und andere Verschärfungen gegenüber Berufsund Gewohnheitstätern bilden den Mittelpunkt der Regierungspropaganda in Bezug auf ihre strengere Strafpolitik. Die ,three strikes and you are out"-Regel in der ursprünglichen Fassung des $\S 81$ Abs. 4, wonach sich gegenüber Tätern von drei Gewaltdelikten die Obergrenze der Strafandrohung auf bis zu lebenslänglich erhöhen konnte, wurde durch das Verfassungsgericht wegen ihrer Unbestimmtheit aufgehoben ${ }^{60}$ - sehr zum Unwillen der Regierung, die diese Verschärfung als Kernstück ihrer Kriminalpolitik angepriesen hatte.

In ihrer Ursprungsfassung enthielten $\S \S 83-84$ Sonderregeln für die Strafzumessung bei einem Vergleich. Diese sind mit der Neuregelung des Strafverfahrens in die neue StPO überführt worden; ${ }^{61}$ im StGB ist nur ein Verweis hierauf verblieben. Falls der Täter seine Schuld zugibt und auf die mündliche Verhandlung verzichtet, kann er

58 Zur Problematik der Mitte-Regelung s. L. Fázsi, M. Toldiné Kulcsár, A középmérték értékének dilemmája, Jogtudományi Közlöny 2016 S. 153-164; B. Gellér, Büntetéskiszabás Magyarország negyedik Büntető Törvénykönyvében, Jogtudományi Közlöny 2015 S. 69-78 (74-75).

59 Kurie, KD 2019 Nr. 318: Die Erhöhung um die Hälfte ist das absolute Obermaß, das sich auch bei mehrfachen Rückfällen nicht weiter verschärfen kann.

60 VerfGE 23/2014. (VII. 15.) AB v. 15.7.2014.

61 Insbesondere $\S \S 731-738$ StPO. Dazu I. Szigeti, Az egyezségre vonatkozó eljárásjogi normarendszer, Magyar Jog 2018 S. 690-698. 
mit dem Staatsanwalt einen Vergleich über das Strafmaß schließen, das auch niedriger als die Mindeststrafandrohung für das verwirklichte Delikt sein kann. Der Vergleich kommt durch die gerichtliche Genehmigung zustande.

Strafen und Maßnahmen werden in das Strafregister eingetragen. Eintragungen sind über die Dauer der Strafe hinaus bei der Verurteilung zu einer Freiheitsstrafe wegen einer Vorsatztat weitere drei bis zehn Jahre einsehbar; in dieser Zeit gilt der Betreffende als vorbestraft ( $\S 97-104)$.

\section{Besonderer Teil}

Eine generelle Tendenz des BT ist die Anhebung des Strafrahmens v. a. bei Straftaten mit Gewaltanwendung. Andererseits werden Vermögensdelikte wie z.B. Diebstahl, Sachbeschädigung, Betrug oder Unterschlagung unterhalb einer Bagatellgrenze als Ordnungswidrigkeit behandelt, sofern sie nicht geschäftsmäßig oder bandenmäßig begangen werden. Diese Wertgrenze definiert $\S 462$ differenziert nach den einzelnen Delikten; für die meisten einschlägigen Tatbestände endet die Ordnungswidrigkeit und beginnt die Straftat (Vergehen) bei einem Wert von 50.000,- HUF. ${ }^{62}$

Im Mittelpunkt der Tötungsdelikte steht ein einheitlicher Tatbestand, die Tötung (emberölés, ${ }^{63} \S 160$ ), die vorsätzlich oder fahrlässig begangen werden kann. Neben diesem Begriff verwendet das StGB das Wort „Mord“ (gyilkosság) nicht. Umstände, die an die deutschen Mordmerkmale erinnern, z.B. vorherige Planung, Gewinnstreben, niedrige Beweggründe oder Zwecke, Unbarmherzigkeit, zulasten mehrerer Personen oder von Amtsträgern, Minderjährigen oder Verteidigungsunfähigen oder Rückfälligkeit wirken strafschärfend. Neben der Tötung kennt das StGB als selbstständige Taten gegen das Leben die Tötung in starker Gemütsaufwallung (§ 161), ${ }^{64}$ die Mitwirkung am Selbstmord eines anderen $(\S 162)^{65}$ und die Abtreibung, v. a. die Fremdabtreibung (§163). ${ }^{66}$

Modern gibt sich das Medizinstrafrecht in Kap. XVI: Eingriff in den menschlichen Genbestand ( $§ 168$ ), verbotene Verwendung menschlicher Geschlechtszellen (§ 169), Wahl des Geschlechts eines ungeborenen Kindes ( $\$ 170)$, Verletzung der Regeln über Forschungen am Menschen ( $\$ 171)$, Verletzung der Regeln über Forschungen mit Embryonen oder Geschlechtszellen ( $\S 172-173)$, Schaffung genetisch identi-

62 Das entspricht etwa 150,- EUR.

63 Im Csemegi-Kodex, der in $\S \S 278-281$ zwischen einer vorsätzlichen Tötung mit Vorbedacht (Mord) und einer vorsätzlichen Tötung ohne Vorbedacht unterschied, war „emberölés“ die letztgenannte Straftat und entsprach damit dem Totschlag in $\S \S 211-212$ dtStGB i.d.F. vom 31.5.1871 bis zum 4.9.1941.

64 Das entspricht dem österreichischen Totschlag gemäß § 76 öStGB.

65 E. Belovics, Az öngyilkosság büntetőjogi értékelésének sajátosságai, Magyar Jog 2014 S. 193-203.

66 Zulässige Selbstabtreibungen sind kein Gegenstand des Straf-, sondern des Krankenversicherungsrechts. Hierzu E. Filó, A magzatvédelmről ismét, Jura 2016 S. 254-257; A. Sebestyén, Az abortuszról és a jogi feminizmusról. Az „,abortusz-tanácsadás“ és az „,abortuszturizmus“ esete Magyarországon, Állam- és Jogtudomány 2018/1 S. 93-110. 
scher menschlicher Individuen $(\S 174)^{67}$ und verbotener Gebrauch des menschlichen Körpers ( $(175)$. Spruchpraxis zu diesen Tatbeständen ist nicht nachweisbar. Im Mittelpunkt des anschließenden Kap. XVII über Gesundheitsgefährdungsdelikte steht das Rauschgift, dessen Besitz schon in kleinsten Mengen strafbar ist. ${ }^{68}$ Zukünftigen Entwicklungen begegnen $\S \S 184-184 / \mathrm{D}$ mit ihrer Strafandrohung für den „Missbrauch neuer psychoaktiver Stoffe“. Eine Legaldefinition der neuen psychoaktiven Stoffe enthält das Arzneimittelgesetz, ${ }^{69}$ auf das $\S 184 / \mathrm{D}$ verweist. Auch das Doping ist als „Missbrauch leistungssteigernder Mittel“ (§ 185) strafbar. Im Rahmen der Verkehrsdelikte erfassen separate Tatbestände das Fahren unter Alkoholeinfluss (§236) und unter Einfluss anderer Mittel, die die Fahrtüchtigkeit einschränken (§ 237).

Das Umweltstrafrecht ${ }^{70}$ unterscheidet zwischen der Schädigung der Umwelt (§ 241) und der Natur ( §§ 242-243). Der erste Tatbestand erfasst die Gefährdung oder Schädigung einzelner Umweltmedien wie Boden, Luft, Wasser, Flora und Fauna, während der zweite verbotene Eingriffe zu Lasten von geschützten Lebewesen, Habitaten oder Naturerscheinungen wie z.B. Höhlen mit Strafe bedroht. In beiden Grundtatbeständen droht dem Täter Freiheitsentzug von bis zu drei Jahren. Zu den Umweltdelikten zählt der Gesetzgeber zudem die Tierquälerei, die Jagd- und Fischwilderei, verbotene Tierkämpfe, Verstöße gegen die Abfallwirtschaft, den Missbrauch von die Ozonschicht gefährdenden Stoffen sowie etliche Tatbestände des Nuklearstrafrechts.

Das Korruptionsstrafrecht in Kap. XXVII umfasst die unmittelbare und mittelba$\mathrm{re}^{71}$ aktive sowie die passive Bestechung sowohl im Geschäfts- als auch im Amtsverkehr ( § 290-296). Die Strafe für das Grunddelikt ist Freiheitsentzug von bis zu drei Jahren; für die Bestechungsannahme seitens Beamter, Richter etc. gilt ein erhöhter Strafrahmen von einem bis fünf Jahren. Weitere Korruptionsdelikte sind das „Handeltreiben mit Einfluss" ( $\S 298-299)$, das eine Art strafbare Lobbytätigkeit darstellt, ${ }^{72}$ und die Unterlassung der Meldung von Korruptionstaten ( $§ 300)$. Insgesamt weitet

67 Auch Art. III. Abs. 3 GrundG beschreibt das Klonen, um dieses Fremdwort zu vermeiden, mit einer gewundenen Formulierung, nämlich „kopieren von Einzelnen“. Zum sprachpolitischen Hintergrund dieses Hyperpurismus s. Jakab (Fn. 24), S. 204.

68 Unter der Geltung der alten Verfassung urteilte das Verfassungsgericht in seinem - dogmatisch noch im sozialistischen Rechtsdenken verhafteten - Urteil 54/2004. (XII. 13.) AB v. 13.12.2004, dass die Verfassung die Strafbefreiung des Besitzes kleiner Mengen für den Eigenbesitz verbiete. Kritisch hierzu u. a. T. Györfi, Üzenet az elefántcsonttoronyból: az Alkotmánybíróság droghatározata, Fundamentum 2005/1 S. 73-85.

69 Gesetz 2005:XCV über die Arzneimittel für die Anwendung am Menschen [...] v. 15.7.2005, MK 2005 Nr. 100 S. 5555; die Aufzählung dieser Stoffe enthält die aufgrund dieses Gesetzes ergangene, laufend aktualisierte Verordnung des Ministers für Humanressourcen 55/2014. (XII. 30.) EMMI. Die notwendige Unbestimmtheit des Strafrechts bei neuen Stoffen ist verfassungskonform: VerfGE 3284/2017. (XI. 14.) AB v. 14.11.2017. Zu den Tendenzen im Drogenstrafrecht $P$. Drávecz, Kihívások az új pszichoaktív anyaggal visszaélés joggyakorlatában: egység, halmazat, prognózis, Magyar Jog 2019 S. 237-246.

70 M. Julesz, Umweltstrafrecht in Ungarn und Deutschland, OER 2013, S. 101-104.

71 Wegen Bestechung macht sich auch strafbar, wer einem anderen Geld gibt, damit dieser einen Amtsträger besticht: Kurie, KD 2017 Nr. 390.

72 Wegen dieses Delikts macht sich strafbar, wer z.B. Angehörigen eines Angeklagten gegen Zahlung einer Geldsumme verspricht, eine milde Strafe bei den zuständigen Behörden zu erwirken: Kurie, KD 2019 Nr. 286. 
das neue StGB die Korruptionstatbestände aus. ${ }^{73}$ Dennoch hat die Praxis bereits mit der strafrechtlichen Bekämpfung der Alltagskorruption wie dem sog. Dankgeld (hálapénz) - das Patienten gegenüber Krankenhäusern, Ärzten und Pflegepersonal zahlen müssen, um überhaupt Zugang zu medizinischen Leistungen $\mathrm{zu}$ erhalten - größte Schwierigkeiten. ${ }^{74}$ Dass die - mittlerweile oft offen zugegebene - ,große Korruption“ durch Regierungsmitglieder, regierungsnahe Oligarchen und deren Günstlinge gar nicht erst angeklagt wird, ist die Hauptaufgabe des Generalstaatsanwalts Péter Polt, den die Zweidrittelmehrheit von Fidesz im Parlament am 7.12.2010 und erneut am 5.11.2019 für jeweils neun Jahre ins Amt gewählt hat. Zum Dank für seine treuen Dienste ernannte Fidesz-Staatspräsident János Áder im Dezember 2017 Péter Polt zum Universitätslehrer, obwohl zuvor die Juristische Fakultät der Universität Budapest (ELTE) die Ernennung von Polt zum Privatdozenten im regulären Verfahren abgelehnt hatte.

Kap. XXXI widmet sich den Verstößen gegen die Vorschriften völkerrechtlicher Verträge. Strafbar sind der Missbrauch verbotener Waffen (§ 326), die Verletzung eines Embargos durch Handeln oder Unterlassen ( $\$$ 327-328) und der Missbrauch von Militärprodukten und Dual-use-Gütern ( $\S$ 329-330). Praktische Relevanz haben diese Vorschriften nicht erlangt.

Die Straftaten gegen die öffentliche Ruhe enthalten umfassen Taten wie Kriegshetze, Hetze gegen eine Gemeinschaft, Leugnung totalitärer Verbrechen, Verletzung nationaler Symbole, Hetze gegen behördliche Anordnungen, Verbreitung von Gerüchten, Drohung mit einer öffentlichen Gefahr, Hooliganismus (für den das StGB, anders als das sowjetisch-russische Recht, nicht diesen Anglizismus verwendet, sondern das ungarische „garázdaság“) und Ordnungsstörung. In der Coronakrise wurde die Verbreitung von Gerüchten um eine „Corona-Lügen-Klausel“" erweitert, wonach mit Freiheitsstrafe zwischen einem und fünf Jahren bestraft wird, wer unwahre oder entstellte wahre Tatsachen so verbreitet, dass der Erfolg von Schutzmaßnahmen gefährdet werden kann, wobei die abstrakte Eignung zur Gefährdung ausreicht. ${ }^{75}$ Der umstrittenste Tatbestand dieses Kapitels ist aber der „Gebrauch von Symbolen der Willkürherrschaft" (§ 335). Zu diesen Symbolen zählt das Gesetz neben dem Hakenkreuz, der SS-Rune, dem Pfeilkreuz (dem Abzeichen der ungarischen Nationalsozialisten) und Hammer und Sichel auch den fünfzackigen roten Stern. Während das ungarische Verfassungsgericht gegen das Verbot des roten Sterns im alten StGB nichts einzuwenden hatte, weil das öffentliche Interesse daran, von Werbung für den Totalitarismus verschont zu bleiben, die Meinungsfreiheit überwiege, sah der EGMR in mehreren Entscheidungen die Redefreiheit verletzt, denn der rote Stern symbolisiere in vielen Staa-

73 M. Hollán, A hivatali befolyás vásárlásáról és tényállásának kibővítéséről, Miskolci Jogi Szemle 2016/2 S. 29-41.

74 M. Hollán, A Kúria ítélete a hálapénzről, Magyar Jog 2016 S. 39-50; I. Ott, A Kúria ítélete hálapénz ügyben - A büntetőjogi hálapénz-fogalom születése, Jogesetek Magyarázata 2015/3, S. 49-52, mit Kommentar von M. Hollán, Jogesetek Magyarázata 2015/4, S. 27-36.

$75 \S 337$ Abs. 2 StGB. Das Strafmaß für die tätliche Behinderung von Seuchenschutzmaßnahmen liegt deutlich darunter. $\mathrm{Zu}$ diesem im Hinblick auf die Meinungs- und Medienfreiheit ebenso wie auf das Grundrecht auf Gesundheit bedenklichen Mediensonderstrafrecht s. $H$. Küpper, Das ungarische Corona-Ermächtigungsgesetz: das „Ende der Demokratie“?, WiRO $2020 / 5$. 
ten keine totalitäre Ideologie, sondern demokratische Parteien und Gewerkschaften. Während der Beratungen zum neuen StGB stellte das ungarische Parlament durch Beschluss klar, dass es mit dem EGMR nicht übereinstimmt und unter Verletzung der Straßburger Rechtsprechung an der Strafbarkeit des roten Sterns festhält; das innenpolitische Kapital aus der symbolischen Verurteilung der kommunistischen Vergangenheit war für die Fidesz-Führung wichtiger als die Einhaltung der EMRK. Nach dem Erlass des StGB erklärte das Verfassungsgericht $\S 335$ wegen seiner zu vagen Formulierung für verfassungswidrig, woraufhin die Vorschrift als konkretes Gefährdungsdelikt neu gefasst wurde. ${ }^{76}$ Die Verurteilungszahlen wegen des Tragens des roten Sterns bewegen sich im einstelligen Bereich.

Als Reaktion auf die Flüchtlingsströme auf der Balkanroute begann Ungarn 2015, Grenzzäune zu bauen, und sicherte diese auch strafrechtlich. In Kap. XXXIV (Straftaten gegen die Ordnung der öffentlichen Verwaltung) wurden im November 2015 die Tatbestände des ,verbotenen Übertritts von Grenzsperren“ (§ 352/A), der „Beschädigung von Grenzsperren“ (§352/B) und der „Verhinderung von Bauarbeiten im Zusammenhang mit Grenzsperren“ ( $(353 / \mathrm{C})$ eingefügt. ${ }^{77}$ Die Beschädigung von Grenzsperren wird mit einem bis zu fünf Jahren Freiheitsstrafe, die einfache Sachbeschädigung ( $\$ 371$ ) hingegen mit bis zu einem Jahr bestraft. Flankiert wird dies durch die denkbar weiteste höchstrichterliche Auslegung des Menschenschmuggels (§353), wonach jeder - auch noch so indirekte - Beitrag zu einer Überschreitung einer Staatsgrenze unter Verletzung von Rechtsvorschriften unter diesen Tatbestand fällt. ${ }^{78} 2018$ wurde die Kriminalisierung derer, die Flüchtlingen helfen, als „Förderung und Unterstützung der rechtswidrigen Einwanderung“ (§ 353/A) ausgeweitet. Danach riskiert eine Arrest- oder sogar Gefängnisstrafe, wer nicht asylberechtigten Personen in ihrem Asylverfahren hilft; da erst am Ende des Asylverfahrens feststeht, ob die unterstützte Person Asyl erhält oder nicht, wälzt $\S 353 /$ A das Strafrisiko des Nichtvorliegens oder der Nichterweislichkeit eines Asylgrundes auf diejenigen über, die einem Asylbewerber durch das ungarische Asylverfahren helfen wollen. Das Verfassungsgericht be-

76 VerfGE 14/2000. (V. 12.) AB v. 12.5.2000 (zum alten StGB); EGMR, Urteile v. 8.7.2008, AZ.: 33629/06, Vajnai./. Ungarn (OER 2008, S. 359), und v. 3.11.2011, AZ.: 29459/10, Fratanoló./. Ungarn (OER 2012, S. 97-98); Parlamentsbeschluss 58/2012. (VII. 10.) OGY über die Annahme des Berichts über die Fragen im Zusammenhang mit der Durchführung des Urteils des Europäischen Menschenrechtsgerichtshofs in Sachen Fratanoló gegen Ungarn v. 10.7.2012, MK 2012 Nr. 89 S. 13357; VerfGE 4/2013. (II. 21.) AB v. 21.2.2013 (OER 2013, S. 359-360). Hierzu s. Küpper in FS Schroeder (Fn. 10), S. 153-155; Küpper in Schroeder/Küpper (Fn. 26), S. 316-318; Küpper, in: Pöschl/Wiederin (Fn. 50), S. 162-163; $R$. Neubauer, E. Körincz, Der rote Stern, das Hakenkreuz, die Meinungsfreiheit, Neue Justiz 2013 S. 500-505.

$77 \mathrm{Zu}$ diesen Tatbeständen als ,symbolisches Strafrecht“ G. Skoda, A szimbolikus jogalkotás a büntetőjogban, Pro Futuro 2018/3 S. 173-190 (185-188).

78 Kurie, KD 2019 Nr. 217: Menschenschmuggel verwirklicht z.B., wer Drittstaatsangehörige von einer Aufnahmeeinrichtung nach Budapest bringt, damit sie sich dort mit Schleppern treffen können, oder wer Drittstaatsangehörigen zum Grenzübertritt geeignete Kleidung verkauft oder ihnen Auskünfte erteilt, wie sie zu dem verabredeten Treffpunkt mit Schleppern gelangen können. 
schränkte die Anwendbarkeit des $\S 353 / \mathrm{A}$ und stellte die selbstlose soziale Hilfe für Asylbewerber straffrei, hielt ihn im Übrigen aber für verfassungskonform. ${ }^{79}$

Heterogen sind die Tatbestände des Kap. XLI mit den Wirtschaftsverbrechen. Dazu zählen die falsche Buchhaltung (§ 403), der Entzug des Eigenkapitals bei Kapitalgesellschaften und Genossenschaften ( $\$ 407)$, die Nichtlieferung obligatorischer Daten an Firmen- und andere Register (§ 409) und die Verletzung von Geheimhaltungspflichten (§ 413) ebenso wie Konkursstraftaten ( $\S 404-404 / A)$, der Deckungsentzug in Bezug auf eine konkrete Forderung aus einem schriftlichen Vertrag (§405), Insiderhandel und Kapitalmarktbeeinflussung ( $\S 410-411)$ sowie Pyramidenspiele (§ 412). Strafbar sind zudem bestimmte Tätigkeiten ohne Genehmigung wie Finanzdienstleistungen ( $§ 408)$ oder, soweit eine Genehmigung erforderlich ist, der Außenhandel (§ 406). Zu allen diesen Delikten gibt es kaum oder gar keine Rechtsprechung. Bei der Anwendung der allgemeinen Vermögensdelikte, insbesondere der Unterschlagung, auf die Wirtschaftskriminalität ergibt sich das Problem, dass dort eine „Sache“ vorausgesetzt wird, der zivilrechtliche Sachenbegriff aber u. a. keine dematerialisierten Aktien umfasst. Der zivilrechtliche Sachenbegriff führt mithin zu einer Strafbarkeitslücke, die Entwicklung eines genuin strafrechtlichen Sachenbegriffs steckt hingegen noch in den Anfängen. ${ }^{80}$

79 VerfGE 3/2019. (III. 7.) AB v. 7.3.2019. Zu diesem Thema E. Amberg, Büntetőjog a bevándorláskezelés eszközrendszerében, Magyar Jog 2016 S. 405-412.

80 M. Hollán, Sikkasztás a dolog büntetőjogi fogalmának határain és azon túl, Magyar Jog 2020 S. 162-178. 